\title{
The Additive Manufacturing Process of Electric Power Fittings Fabricated by Metal Droplet Deposition
}

\author{
Haihua Wu ${ }^{1}$, Guangxi Zhao ${ }^{2}$, Zhengying Wei ${ }^{{ }^{*}, 2}$ \\ ${ }^{1}$ College of Mechanical \& Power Engineering, China Three Gorges University \\ ${ }^{2}$ The State Key Laboratory for Manufacturing Systems Engineering, Xi'an Jiaotong University
}

*Corresponding Author: Zhengying Wei, zywei@mail.xjtu.edu.cn

Abstract:

Metal droplet deposition is a kind of additive manufacturing (3D Printing) technique that fabricates near-net part through droplets deposition with lower cost and higher efficiency. This paper proposed a solution to problems of electric power fittings that large inventories, high procurement costs, low manufacturing efficiency and transportation cost. Using additive Manufacturing technique - metal droplet deposition, electric power fittings fabricated on power construction site. This paper describes the manufacturing process of typical thin-walled samples (the structure optimized based on additive manufacturing principle) and ball head rings of electric power fittings. Aiming at the integral AM forming for ball and ball socket electric power fitting workpiece, a novel easy removal forming support material (ceramics and gypsum mixed with UV cured resin) have been developed. Here this support material was used to fabricate nested integral workpieces. Dimensional accuracy and microstructure of the test pieces were analyzed. The error of the height and width of the forming workpiece is within $5 \%$. No obvious overlap trace (such as overlap line and cracks) observed, and the internal microstructure is equiaxial crystal. The average density of the component is $99.51 \%$, which measured by drainage method and $13.39 \%$ higher than the cast raw material.

Keywords: Additive manufacturing; Metal droplets; Electric power fittings; Thin-walled sample; Ball head rings workpiece.

Citation: H.H. Wu, G.X. Zhao, Z.Y. Wei, The Additive Manufacturing Process of Electric Power Fittings fabricated by Metal Droplet Deposition. Mech Eng Sci, 2019,1(1): 27-32. https://doi.org/10.33142/me.v1i1.658

\section{Introduction}

Metal additive manufacturing (3D printing) of metallic materials has become a research hotspot in additive manufacturing (AM) technology ${ }^{[1-2]}$, which fabricates functional component directly. Currently, high power laser or electron beam are adopted as heat source in metal 3D printing ${ }^{[3-4]}$, and raw materials are usually in powder or wire form, leading to high cost and material limitations. As a result, it is necessary to propose a new metal additive manufacturing technology that cost saving and high efficiency. In this paper a 3D printing device has been established for fabricating electric power fittings using electromagnetic induction as the heat source.

At present, the main forming methods of electric power fittings are casting and forging. The issues that large inventories, high procurement costs, low manufacturing efficiency and transportation cost have caused great economic losses. Therefore, it is significant to fabricate electric power fittings on power construction site using high efficiency and low-cost metal 3D printing process according to site requirement.
Metal droplet deposition is an additive manufacturing process during which workpieces are fabricated from molten materials without mould or other tooling. Workpieces are fabricated by droplets deposition layer-by-layer which belongs to near net shape methods. Electric power fittings are fabricated by metal droplet deposition process, satisfying the electrical repairs requirements, while reducing assembly costs and achieving zero inventories.

Researchers at the University of Toronto ${ }^{[5-6]}$ researched 3D printing technology of tiny metal workpieces, which uses pulsed air pressure to melt low-melting tin-lead metals under a pneumatic pulse. The lead or tin metal droplets with diameters between 100 and $300 \mu \mathrm{m}$ printed by layer-by-layer stacking of droplets ${ }^{[7]}$, Lee ${ }^{[8]}$ produced uniform solder droplets with a molten metal inkjet system, but the material is limited to low melting metal materials. Wenbin ${ }^{[9]}$ researched the droplet deposition process of metal workpieces and intermetallic compound materials, but the surface quality is low. Xiong and Ando established the numerical analysis models with different overlapping conditions ${ }^{[10-11]}$. Trapaga studied the spreading and solidifi- 
cation mechanism of the droplets deposition within a narrow space and large temperature gradient ${ }^{[12]}$. The numerical analysis and experimental varication were used to investigate the metal droplet deposition and spreading with different process parameters, such as droplet size, displacement and substrate temperature. At present, the numerical simulation works ${ }^{[13-15]}$ of droplets deposition and overlap processes were mainly based on simple prototypes, which couldn't reflect practical application value of the deposition process.

In this paper, the process test is carried out for typical electric power fittings with cantilever structure, and the forming accuracy and microstructure of the forming workpieces are analyzed. The functional parts of electric power fittings were fabricated by successive deposition and solidification of molten aluminium droplets on a horizontally $\mathrm{Al}$ alloy substrate, and the microstructure and performance of deposition parts were also analyzed. The morphology and the influences of the internal quality of the droplets on the cross-sectional feature were revealed. The results could provide technical support and reference to the electric power fittings forming.

\section{Experimental system and Methods}

\subsection{Experimental system}

Figure 1 shows a conceptual view of the droplet deposition process. It mainly consisted of a pneumatic system, a motion control system, a forming process monitoring system and an inert environment control system. The pneumatic system is used to produce metal droplets on demand. It includes a droplet controller, a solenoid valve, a crucible, a heating furnace and a nitrogen gas resource. The motion control system is used to form the workpieces by controlling the motion of a $3 \mathrm{D}$ platform according to data information. It consisted of a PMAC (program multiple axes controller), a 3D movement platform and the deposition substrate. The forming process monitoring system composed by a CCD camera and an image acquisition card is used to observe the deposition process of droplets. The inert environment control system is made up of glove box and gas circulating device. It is used to prevent the metal from being oxidized. The whole process is coordinately controlled by industrial computer to complete the fabrication of workpieces.

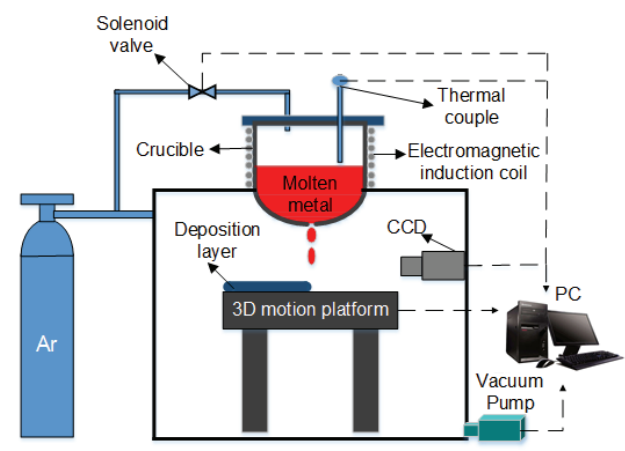

Figure 1 Schematic diagram of droplet deposition system

Figure 2 shows the experimental system of droplet deposition according to above schematic diagram. The equipment mainly includes pneumatic drive system, droplet deposition system, inert gas protection system and three-dimensional motion translation stage. The photograph in Figure 2 shows the manufacturing system established by the scholars in Xian JiaoTong University (China) ${ }^{[16-17]}$.

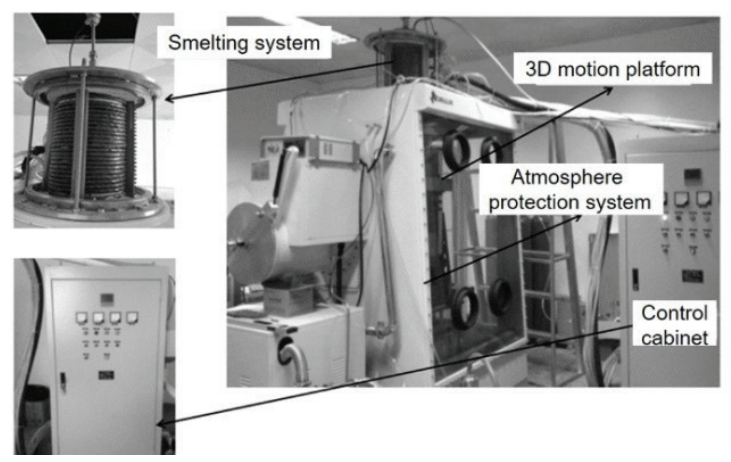

Figure 2 Experimental system of droplet deposition

\subsection{Manufacturing parameters of electric power fittings}

A variety of electric power fittings are exhibited in Figure 3. It can be seen that there are so many kinds of electric power fittings. So, a typical component that a movable joint with hollow structures (shown in Figure 4) were selected for the forming research. As shown in Figure 5, the movable joint mainly consists of a thin-walled workpiece and a ball head ring workpiece. As long as the parts shown in Figure 4 can be processed by the droplet deposition process, almost all the forming of the electric power fittings can be realized.

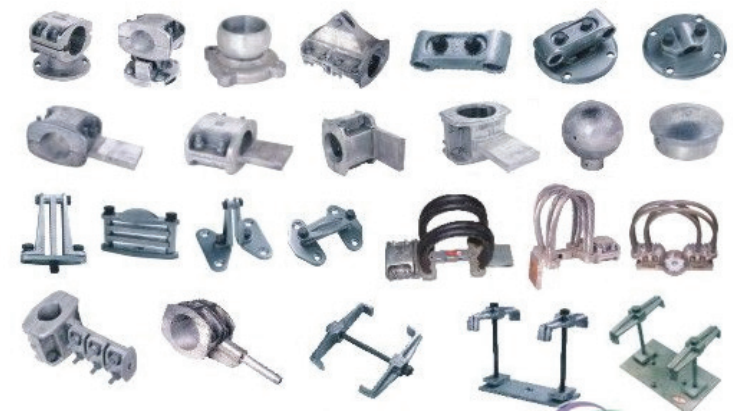

Figure 3. Structure of the electric power fittings

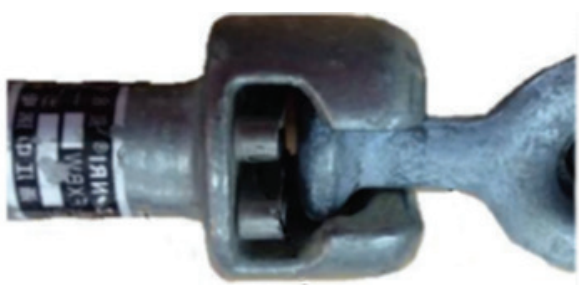

Figure 4. The movable joint with hollow structure

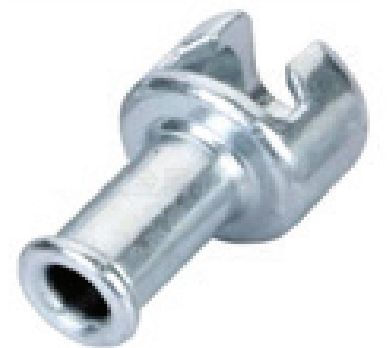

Figure 5(a) Typical thin-walled workpiece 


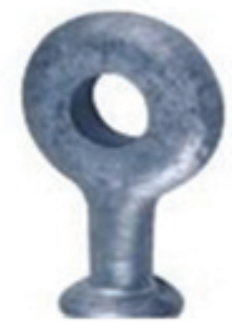

Figure 5(b) Ball head ring workpiece

One of the advantages of additive manufacturing technology is the ability to simplify complex assemblies into one functional part. As shown in Figure 6a to Figure 6c, the structure of typical thin-walled workpiece was redesigned based on the characteristics of metal droplet deposition. The thin-walled workpiece with $100 \mathrm{~mm}^{\star} 2 \mathrm{~mm}$ dimension was fabricated by molten droplets depositing sequentially layer by layer. The experimental parameters were shown in Table 1.

Table 1 Process parameters of typical Electric Power Fittings

\begin{tabular}{|l|l|}
\hline Parameter & Value \\
\hline Scanning speed $\left(\mathrm{mm}^{`}{ }^{-1}{ }^{-1}\right)$ & 30 \\
\hline Droplets temperature $(\mathrm{K})$ & 950 \\
\hline Substrate temperature $(\mathrm{K})$ & 400 \\
\hline Nozzle diameter $(\mathrm{mm})$ & 0.7 \\
\hline Pulse pressure $(\mathrm{Mpa})$ & 0.4 \\
\hline Oxygen content $(\mathrm{PPM})$ & 20 \\
\hline Frequency $(\mathrm{Hz})$ & 30 \\
\hline Manufacturing time $(\mathrm{min})$ & 12.5 \\
\hline Interlayer height $(\mathrm{mm})$ & 1 \\
\hline
\end{tabular}

During the manufacturing process, droplets with initial temperature of $950 \mathrm{~K}$ were generated and deposited onto a $400 \mathrm{~K}$ substrate. Deposition experiments were carried out in glove box under inert atmosphere with low oxygen content (below $20 \mathrm{ppm}$ ). The argon gas pulses were imposed by a solenoid value onto the molten metal in crucible with a $0.4 \mathrm{MPa}$ pulse pressure and a $30 \mathrm{~Hz}$ pulse frequency. Therefore, the uniform droplets are ejected from the nozzle with a diameter of $0.5 \mathrm{~mm}$ at the bottom of the crucible, which is wrapped by a resistance heating ring. In order to stabilize the morphology and dynamic behavior of droplets, the distance between nozzle and substrate is $5 \mathrm{~mm}$. The time it takes to fabricate the typical thin-walled workpiece is $12.5 \mathrm{~min}$, when the displacement speed is $30 \mathrm{~mm} / \mathrm{s}$ and the height interval of adjacent layer is $1 \mathrm{~mm}$.

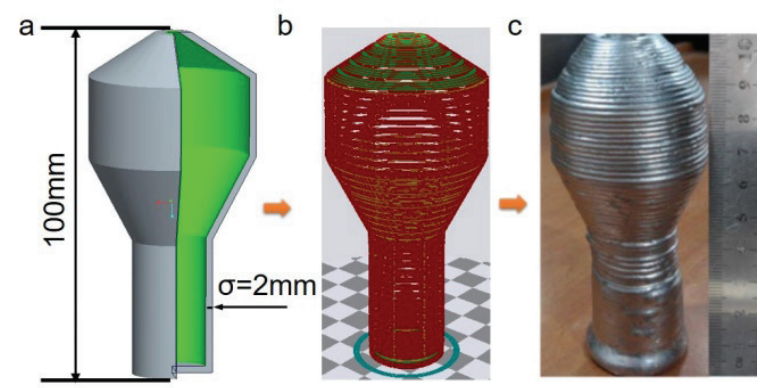

Figure 6 Structure of typical thin-walled workpiece. (a) Model (b) schematic diagram of layer slices (c) workpiece fabricated by droplets
As is shown in Figure 7, the ball head ring workpiece 85 $\mathrm{mm}$ in length, $42 \mathrm{~mm}$ in width and $12 \mathrm{~mm}$ in height and $15 \mathrm{~mm}$ of the inner diameter. According to the influencing factors of droplet deposition process, the stratified cross section is shown in Figure 7b, the suitable parameters such as scanning speed, droplet temperature and nozzle diameter were selected, Workpiece of ball head ring after rough grinding is shown in Figure 7c. The process parameters of deposition of ball head ring workpiece are the same with the parameters of thin-walled workpiece except the interlayer space. The time used for building the ball head ring workpiece was $13.5 \mathrm{~min}$, when the scanning speed was $30 \mathrm{~mm} / \mathrm{s}$ and interlayer spacing was $0.6 \mathrm{~mm}$.
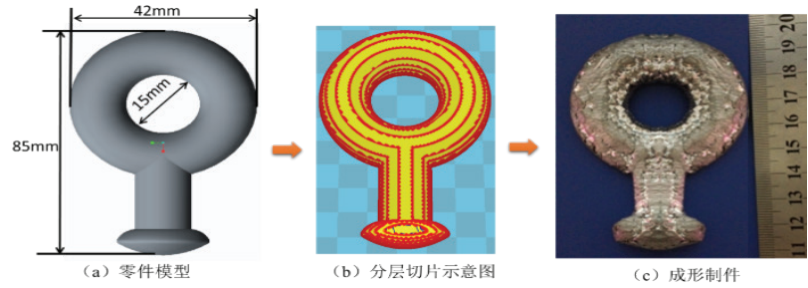

Figure 7 Structure of ball head ring workpiece. (a) Model; (b) Schematic diagram of layered slices; (c) The workpieces fabricated by droplets

\subsection{Investigation on supporting materials}

Due to the existence of cantilever and movable joints, it is necessary to add support during the metal droplet deposition forming process, otherwise collapse and joint immobility will occur. Based on the principle of metal droplet deposition process, it can be known that good supporting properties, fluidity, high temperature resistance and removable property are required for supporting material. As shown in Figure 8, supporting material performance testing device mainly consisted of a pneumatic system, a nozzle, a 3D motion platform and corresponding control software. The pressure control device controls the outlet pressure of the pressure tank to extrude the support material out of the nozzle stably. Simultaneous, the $3 \mathrm{D}$ motion platform moves under the control of the pre-set path until the desired support is formed. In this paper, water, gypsum powder, sand, ceramic powder, and resin were mixed in different proportions to develop supporting materials.

Forming process diagram of suspended structure was shown in Figure 9. The two nozzles were alternately operated, one nozzle was provided with the metal material to be formed, and the other nozzle was filled with the suitable supporting material. Firstly, the metal substrate was deposited layer by layer by droplet deposition, and then the supporting material of a specified shape was deposited under the suspended portion of the power fitting. Furthermore, the cantilever structure was deposited on the supporting material and finally the supporting material was removed to complete the forming of the cantilever.

\section{Results and Discussion}

\subsection{Forming accuracy of droplet deposition}

The height and thickness of the experimental measurements are shown in Table 2 by multiple measurements. It can be seen that the relative error in height direction is small, but it is larger in 
thickness direction. This is due to that the relative error of height direction is more prominent than that in thickness direction during deposition. The experimental results verify the correctness and feasibility of the typical thin-walled workpiece prepared by droplet deposition process, and provide a new method for the research of thin-walled workpiece.

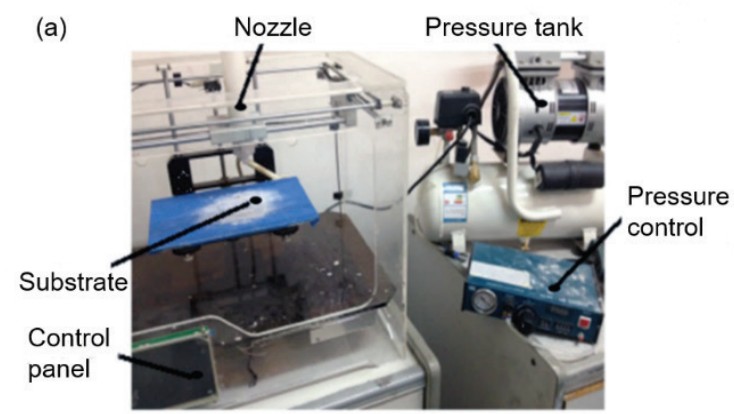

(b)

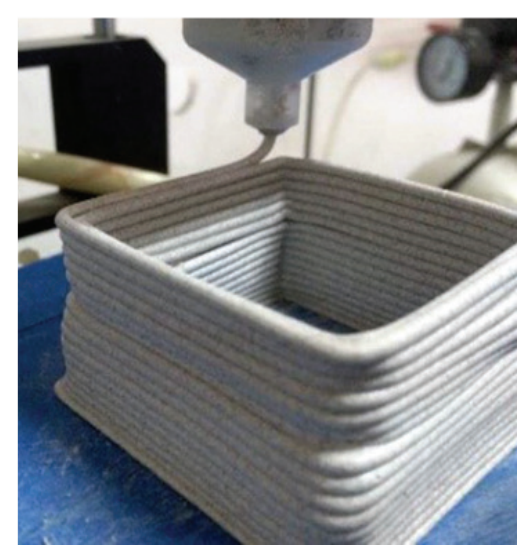

Figure 8 Testing device of supporting material performance
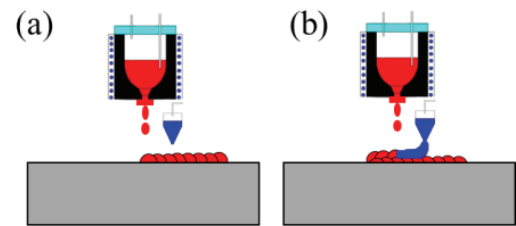

(c)

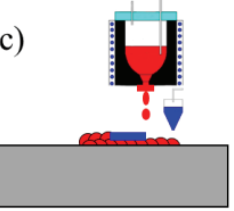

(d)

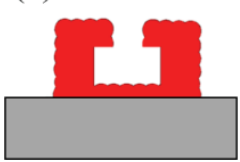

Figure 9 Forming process diagram of suspended structure

In order to verify the manufacturing accuracy of the ball head ring workpiece, by using the method of averaging through multiple measurements, the dimensional accuracy of the forming part was measured and analysed and the results are shown in table 3.

3.3 Performance test of the supporting material and nested integral workpiece

The different proportions and properties of supporting material are shown in Table 4.
As is shown in Table 4, No.3, No.4 and No.5 have high supporting strength and better surface quality so that they are suitable, and their accuracy retaining abilities were further tested, respectively. Initial samples were rectangular with a cylindrical hole, and the dimensions of the hole were measured after 12 hours standing. Results are shown in Table 5.It can be seen from Table 5 that No. 5 supporting material has the best accuracy retaining ability so it was adopted to process suspended structure. Comparison of electric power fittings structure is shown in Figure 10. (a)

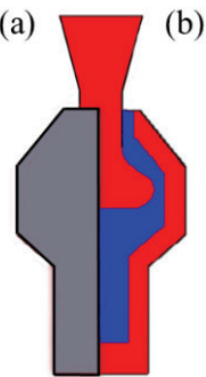

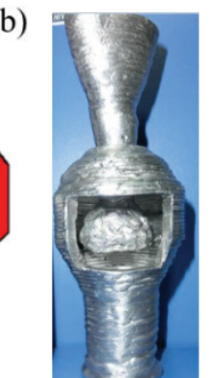

(c)

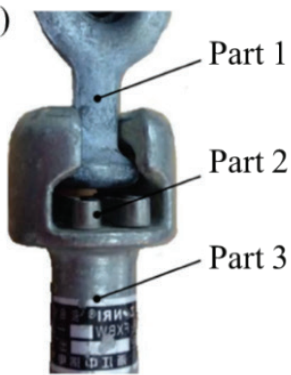

Figure 10 Electric power fittings. (a) model (b) Experimental piece (c) Original component

As shown in Figure 10, complex nested component was fabricated by metal droplet deposition with supporting material. Compared with traditional subtractive method, the workpiece is simplified as an integral structure, which can greatly reduce the assembly cost.

\subsection{Microstructure Analysis}

The formed end-shapes were examined by SEM (scanning electron microscope). The droplet diameter was maintained at a size of about $100 \mu \mathrm{m}$ in all experiments because at this size, the resulting droplets were the most stable. The initial droplet diameter was measured by integrating Nikon AF Micro $200 \mathrm{~mm}$ and Monarch Nova-Strobe BBX 115/230 Digital Portable Stroboscope.
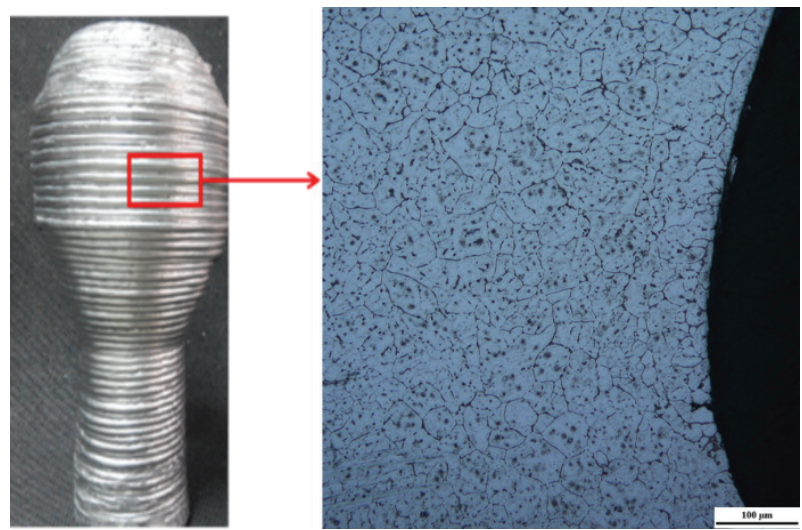

Figure 11 Microstructure of overlap area

As illustrated in Figure 11, no obvious overlap trace (such as overlap line and cracks) was observed, and the internal microstructure is equiaxial crystal.

\subsection{Density Measurement}

Density was measured by drainage method, measuring principle diagram of which is shown in Figure 12. 


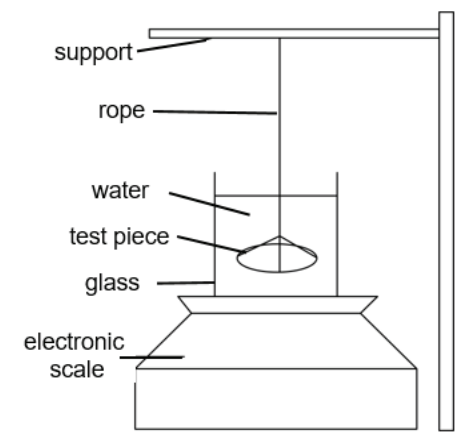

Figure 12 Measuring principle diagram of density

Measure the mass of the test piece in the air and marked as $\mathrm{m} 1$, and put a cup of water on an electronic scale and set the display to zero. Immerse the test piece in water, ensuring that the water doesn't spill and that the test piece doesn't touch the bottom of the cup and marked the display as $\mathrm{m} 2$. The actual density of droplet deposition component can be expressed as:

$$
\rho_{\text {test }}=\frac{m_{1}}{m_{2}} \rho_{\text {water }}
$$

Densification degree can be calculated by:

$$
D=\frac{\rho_{\text {test }}}{\rho_{\text {theory }}}
$$

This paper takes six pieces of droplet deposition components and raw casting material respectively for densification test, results are shown in Figure 13.

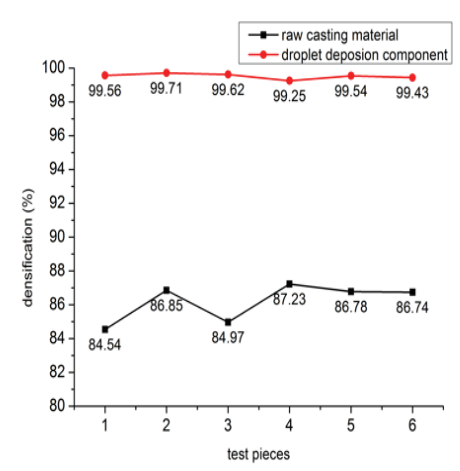

Figure 13 Density of test pieces

Table 2 Height and thickness measurement results of typical thin-walled workpiece

\begin{tabular}{llcc}
\hline & Five measurement values $/ \mathrm{mm}$ & Average value $/ \mathrm{mm}$ & relative error \\
\hline Height & $101 ; 98 ; 102 ; 101 ; 100$ & 100.4 & $0.4 \%$ \\
Thickness & $2.05 ; 2.10 ; 2.12 ; 1.96 ; 1.92$ & 2.03 & $1.5 \%$ \\
\hline
\end{tabular}

\begin{tabular}{cccc} 
Thickness & $2.05 ; 2.10 ; 2.12 ; 1.96 ; 1.92$ & 2.03 & $1.5 \%$ \\
\hline & Table 3 Measurement results of ball head ring workpiece dimension & \\
\hline Height & Five measurement values $/ \mathrm{mm}$ & Average value $/ \mathrm{mm}$ & relative error \\
Thickness & $85.8 ; 86.3 ; 85.3 ; 85.7 ; 85.9$ & 85.8 & $0.94 \%$ \\
diameter & $42.8 ; 43.6 ; 42.3 ; 42.7 ; 43.1$ & 42.9 & $2.14 \%$ \\
\end{tabular}

\begin{tabular}{|c|c|c|c|c|c|c|c|c|}
\hline NO & $\begin{array}{l}\text { gypsum } \\
\text { powder/g }\end{array}$ & $\begin{array}{c}\text { ceramic } \\
\text { powder/g }\end{array}$ & Sand/g & $\begin{array}{l}\text { Photosensitive } \\
\text { resin } / \mathrm{ml}\end{array}$ & $\begin{array}{c}\text { Water/ } \\
\mathrm{ml}\end{array}$ & $\begin{array}{l}\text { Supporting } \\
\text { strength }\end{array}$ & $\begin{array}{l}\text { Surface } \\
\text { quality }\end{array}$ & Extrusion performance \\
\hline 1 & 62 & 62 & 0 & 0 & 40 & -- & -- & Hard to squeezed out \\
\hline 2 & 62 & 62 & 0 & 0 & 50 & High & Good & $\begin{array}{l}\text { Squeezed out but solidified } \\
\text { too fast }\end{array}$ \\
\hline 3 & 62 & 0 & 0 & 25 & 0 & High & better & Squeezed out, no solidification \\
\hline 4 & 62 & 62 & 0 & 35 & 0 & High & better & Squeezed out, no solidification \\
\hline 5 & 62 & 62 & 62 & 48 & 0 & High & better & Squeezed out, no solidification \\
\hline 6 & 62 & 0 & 25.5 & 0 & 88 & Higher & Good & $\begin{array}{l}\text { Squeezed out but solidified } \\
\text { too fast }\end{array}$ \\
\hline
\end{tabular}

Table 4 Proportions and properties of supporting material

\begin{tabular}{|c|c|c|c|c|c|c|c|c|c|}
\hline NO. & placement methods & \multicolumn{4}{|c|}{ Diameter/mm } & \multicolumn{4}{|c|}{ Depth/mm } \\
\hline \multirow[t]{2}{*}{3} & Initial sample & \multicolumn{4}{|c|}{10} & \multicolumn{4}{|c|}{7} \\
\hline & After 12h (without light) & \multicolumn{4}{|c|}{10.5} & \multicolumn{4}{|c|}{6} \\
\hline \multirow[t]{2}{*}{4} & Initial sample & \multicolumn{2}{|c|}{8} & \multicolumn{2}{|c|}{8} & & \multicolumn{3}{|c|}{9} \\
\hline & After $12 \mathrm{~h}$ (with light) & \multicolumn{2}{|c|}{8.5} & \multicolumn{2}{|c|}{7.8} & & \multicolumn{3}{|c|}{9.2} \\
\hline \multirow[t]{2}{*}{5} & Initial sample & 12 & 12 & 12 & 12 & 8 & 8.5 & 9 & 9 \\
\hline & After $12 \mathrm{~h}$ (with light) & 12 & 12 & 12 & 12 & 8 & 8.6 & 9 & 9 \\
\hline
\end{tabular}

Table 5 Results of accuracy retaining abilities 
The average density of droplet deposition component and raw casting material were respectively $99.51 \%$ and $86.12 \%$. Droplet deposition isn't like casting which usually has defects such as air entrainment and shrinkage, so that the densification is higher.

\section{Conclusions}

In this paper, the functional parts of electric power fittings were fabricated by successive deposition with a suitable supporting material, and the microstructure and performance of deposition parts were also analyzed. Experiments proved that the typical electric power fittings fabricated by droplets depositing satisfied the using requirements.

(1) Using the process parameters shown in Table 1, such as substrate temperature and moving speed, the droplet deposition process was experimentally investigated. It is found that the relative error of dimension is less than $5 \%$.

(2) Aiming at the integral AM forming for the typical electric power fitting workpiece, the composition and performance of forming support material were researched. The optimal support material composition and configuration are shown in the fifth group of schemes in Table 4. Nested integral workpieces were fabricated with this support material.

(3) Dimensional accuracy and microstructure analysis of the workpieces were carried out. No obvious overlap trace (such as overlap line and cracks) was observed, and the internal microstructure is equiaxial crystal.

(4) Density of the metal droplet deposition workpiece was measured by the drainage method. The average density of droplet deposition components is $99.51 \%$, which is much higher than the cast raw material.

Acknowledgements: This research was funded by National Natural Science Foundation of China under grant number 51575313 and 51775420 . This paper got help from Du Jun and Wang Xin of Xian Jiaotong University.

\section{References}

[1] Frazier, W. E. (2014). Metal additive manufacturing: a review. Journal of Materials Engineering and Performance, 23(6), 1917-1928.

[2] Wong, K. V., \& Hernandez, A. (2012). A review of additive manufacturing. ISRN Mechanical Engineering, 2012.

[3] Zhang, B., Li, Y., \& Bai, Q. (2017). Defect formation mechanisms in selective laser melting: a review. Chinese Journal of Mechanical Engineering, 30(3), 515-527.

[4] Parthasarathy, J., Starly, B., Raman, S., \& Christensen, A. (2010). Mechanical evaluation of porous titanium (Ti6Al4V) structures with electron beam melting (EBM). Journal of the mechanical behavior of biomedical materials, 3(3), 249-259.
[5] Cheng, S., \& Chandra, S. (2003). A pneumatic droplet-on-demand generator. Experiments in fluids, 34(6), 755-762.

[6] Cheng, S. X., Li, T., \& Chandra, S. (2005). Producing molten metal droplets with a pneumatic droplet-on-demand generator. journal of materials processing technology, 159(3), 295-302.

[7] Fang, M., Chandra, S., \& Park, C. B. (2007). Experiments on remelting and solidification of molten metal droplets deposited in vertical columns. Journal of Manufacturing Science and Engineering, 129(2), 311-318.

[8] Lee, T. M., Kang, T. G., Yang, J. S., Jo, J., Kim, K. Y., Choi, B. O., \& Kim, D. S. (2008). Drop-on-demand solder droplet jetting system for fabricating microstructure. IEEE Transactions on Electronics Packaging Manufacturing, 31(3), 202-210.

[9] Cao, W., \& Miyamoto, Y. (2006). Freeform fabrication of aluminum parts by direct deposition of molten aluminum. Journal of Materials Processing Technology, 173(2), 209212.

[10]Xiong, X., Zhang, H., \& Wang, G. (2009). Metal direct prototyping by using hybrid plasma deposition and milling. journal of materials processing technology, 209(1), 124130.

[11]Ando, T., Chun, J., \& Blue, C. (1999). Uniform droplets benefit advanced particulates. Metal Powder Report, 3(54), 30-34.

[12] Trapaga, G., Matthys, E. F., Valencia, J. J., \& Szekely, J. (1992). Fluid flow, heat transfer, and solidification of molten metal droplets impinging on substrates: comparison of numerical and experimental results. Metallurgical Transactions B, 23(6), 701-718.

[13]Noecker, F. F. I. I., \& DuPont, J. N. (2002). Functionally graded copper-steel using LENS Process. Rapid Prototyping of Materials, 139-147.

[14] Matsumoto, M., Shiomi, M., Osakada, K., \& Abe, F. (2002). Finite element analysis of single layer forming on metallic powder bed in rapid prototyping by selective laser processing. International Journal of Machine Tools and Manufacture, 42(1), 61-67.

[15]Peng, L., Shengqin, J., Xiaoyan, Z., Qianwu, H., \& Weihao, X. (2007). Direct laser fabrication of thin-walled metal parts under open-loop control. International Journal of Machine Tools and Manufacture, 47(6), 996-1002.

[16]Liu, J. H., Shi, Y. S., Lu, Z. L., Xu, Y., Chen, K. H., \& Huang, S. H. (2007). Manufacturing metal parts via indirect SLS of composite elemental powders. Materials Science and Engineering: A, 444(1-2), 146-152.

[17] Shellabear, M., Danzig, A., Heugel, M., Kotila, J., \& Nyrhilä, O. (2001). The breakthrough to 20 micron layers-Increasing precision and efficiency in Direct Metal Laser-Sintering. Proceedings of the uRapid, 256-267. 